de interacções proteína-proteína com propriedades "drug-like" e de estudos de dinâmica funcional e de mecanismos de propagação alostérica de sinal em proteínas.

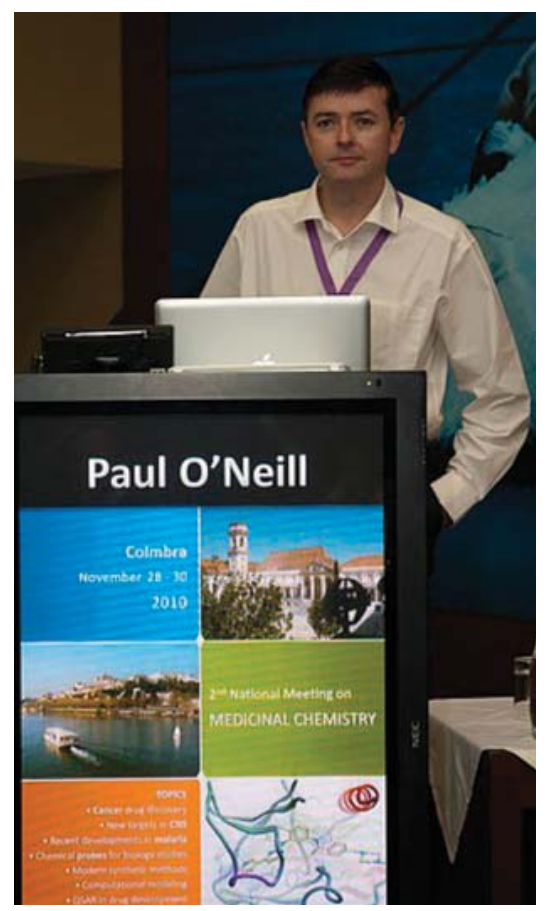

Sessão plenária proferida pelo Professor Paul O'Neill (University of Liverpool)
Paul O'Neill, da University of Liverpool, apresentou o tema: "Synthetic endoperoxide antimalarial; identification of a drug development candidate and back-up molecules with superior properties to the artemisins and OZ277". Esta plenária focou os estudos para a elucidação de mecanismos de acção deste tipo de antimaláricos, o uso de dois componentes activos numa só entidade química e um estudo muito completo de optimização de antimaláricos endoperóxidos.

Heinz Beck, da University of Bonn Medical Center, proferiu a "Lecture BIAL", intitulada "New molecular targets for drug discovery in CNS: Linking the target to the disease(s)", em que abordou a epilepsia, os conceitos que explicam a resistência aos fármacos e os mecanismos de acção emergentes, a nível celular e molecular, que poderão levar a novas estratégias para o desenvolvimento de novas terapêuticas.

Foram ainda apresentadas 27 comunicações orais seleccionadas e 200 comunicações em painel, que aborda- ram tópicos interdisciplinares em Química Terapêutica e que contribuíram para o sucesso desta reunião científica, demonstrando o interesse dos investigadores mais jovens por esta área da Química, os quais responderam cabalmente ao nosso encorajamento para participarem e comunicarem neste forum.

Nesta conferência teve ainda lugar a reunião do Grupo de Química Terapêutica, onde mereceu especial destaque a notícia da candidatura do Grupo/SPQ, recentemente aprovada pela European Federation for Medicinal Chemistry, EFMC, para a realização do XXIIIrd International Symposium on Medicinal Chemistry, o EFMC-ISMC 2014, em Lisboa.

Nesta reunião foi eleita a nova Comissão Directiva, que passou a ser composta pelos Profs. Artur Silva, Fernanda Proença, Madalena Pinto e Rui Moreira.

M. Luísa Sá e Melo (samelo@ci.uc.pt) Presidente da Comissão Organizadora

\title{
$4^{\circ}$ Encontro Nacional de Espectrometria de Massa (MS2010)
}

A espectrometria de massa é uma das áreas de investigação científica mais importantes na actualidade e o suporte analítico e instrumental em diversos domínios científicos, destacando-se a química, as ciências da vida, saúde, ambiente, proteómica e nanotecnologias. Entre 1906 e 2005 foram atribuídos cinco prémios Nobel pelo desenvolvimento da espectrometria de massa, sendo de realçar em 2002 John Fenn e Koichi Tanaka, galardoados com o prémio Nobel da Química pelo desenvolvimento de métodos de desadsorção/ionizaçao suave para a análise por espectrometria de massa de macromoléculas biológicas, que abriu caminho para a universalidade da espectrometria de massa.

A espectrometria de massa tem uma forte tradição em Portugal e grande prestigio internacional, tendo sido recentemente reforçada e consolidada através da criação da Rede Nacional de Espectrometria de Massa (rnem.fc.ul.pt).

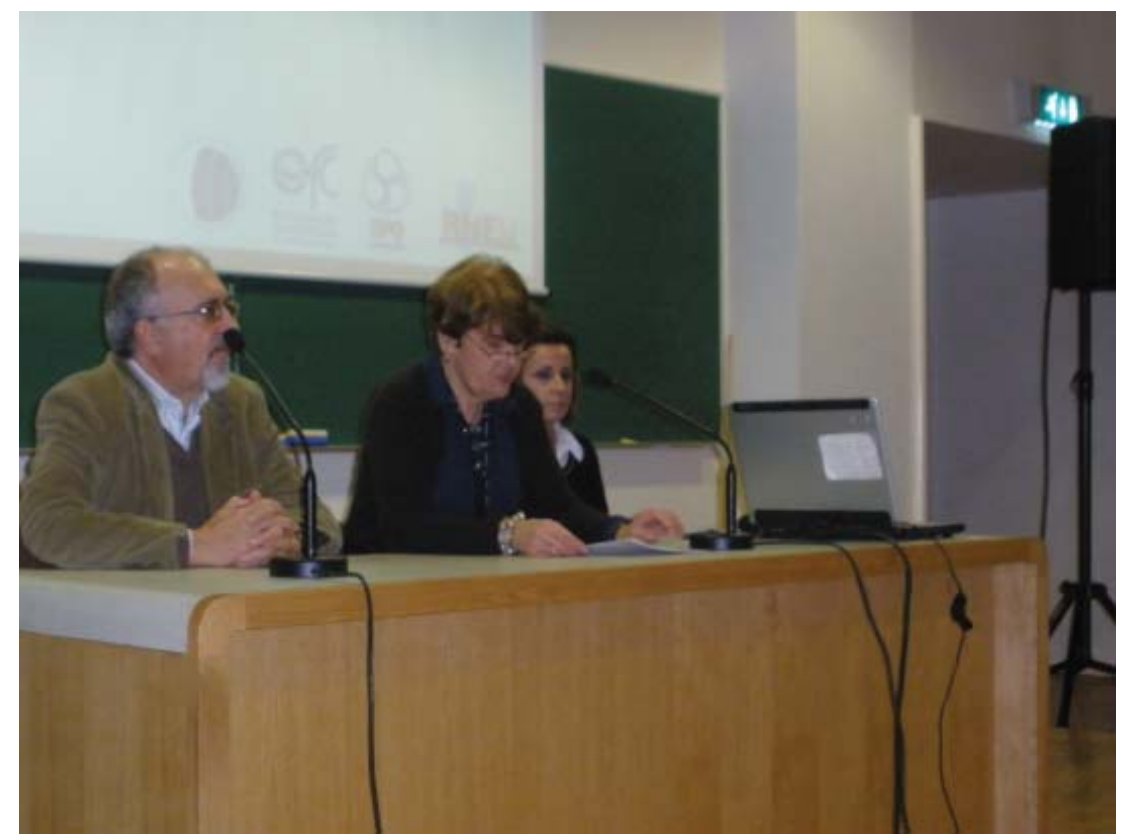

Figura 1 - Cerimónia de abertura do $4^{\circ}$ Encontro Nacional de Espectrometria de Massa, co-organizado pela Faculdade de Ciências da Universidade de Lisboa, Sociedade Portuguesa de Química e Rede Nacional de Espectrometria de Massa. A abertura foi realizada pela

Professora Helena Florêncio, Coordenadora da Rede Nacional de Espectrometria de Massa (ao centro) e contou com a presença do Presidente do Departamento de Química e Bioquímica e Coordenador do Centro de Ciências Moleculares e Materiais da FCUL, Professor Carlos Nieto de Castro e da Professora Ana Ponces Freire, Coordenadora do Centro de Química e Bioquímica da FCUL. Estes dois Centros de Investigaçao da FCUL albergam cerca de duas centenas de investigadores e têm a classificação de Very Good e Excellent, respectivamente 
Com o importante apoio da Sociedade Portuguesa de Química, realizouse na Faculdade de Ciências da Universidade de Lisboa, entre 13 e 15 de Dezembro de 2010, o $4^{\circ}$ Encontro Nacional de Espectrometria de Massa, que contou com 88 inscritos, 6 palestras convidadas, 18 comunicações orais e 62 posters (ms2010.fc.ul. pt). A língua oficial foi o inglês devido à sua projecção internacional. O encontro teve início com uma apresentação pela Professora Helena Florêncio, coordenadora da Rede Nacional de Espectrometria de Massa, que destacou a evolução desta área em Portugal e as suas perspectivas no futuro próximo (Figura 1).

A primeira palestra científica foi efectuada pelo Professor Albert Heck, Coordenador do Centro Holandês de Proteómica, um dos centros mundiais mais importantes nesta área, congregando seis Universidades e diversas empresas. O Professor Albert Heck é um dos pioneiros na investigação de estruturas macromoleculares como cápsulas virais e o proteassoma. Este encontro constituiu uma excelente oportunidade para a realização de palestras por cientistas convidados com grande experiência, como o Professor Ferrer Correia da Universidade de Aveiro (Mass Spectrometry of Oligonucleotide Noncovalent Aducts), e por jovens investigadores. Todas as áreas e aplicações da espectrometria de massa estiveram representadas, desde o ambiente, ao desenvolvimento instrumental, passando pela investigação fundamental em química e pelas áreas biológicas, incluindo a proteómi$\mathrm{ca}$, tendo sido apresentados trabalhos por entidades como a EPAL e a Polícia Judiciária. As empresas internacionais que patrocinaram o evento fizeram-se representar por cientistas directamente responsáveis pelo desenvolvimento experimental e de novas aplicações.

A troca de experiências e o estabelecimento de novas colaborações foi a tónica em muitas das discussões em redor das comunicações em formato de poster (Figura 2).

Tiveram ainda lugar duas importantes reuniões, uma da Rede Nacional de Espectrometria de Massa e outra, aberta a todos os que nela quiseram

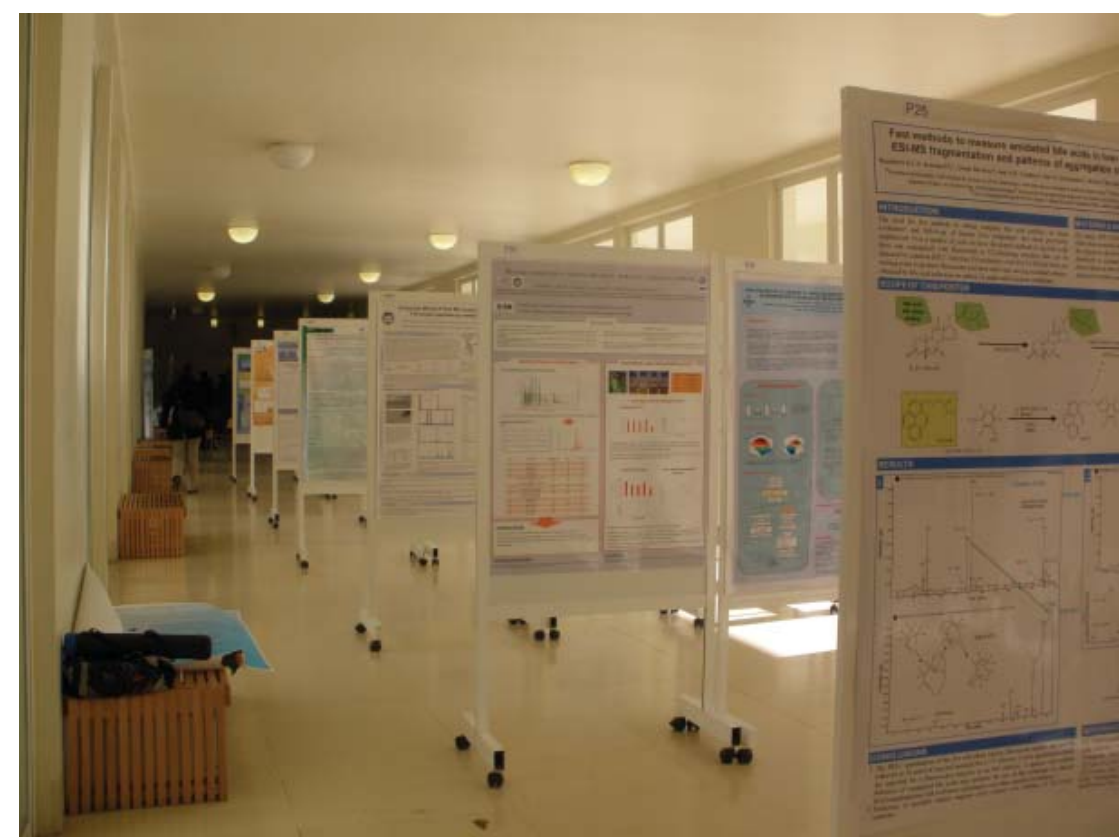

Figura 2 - Vista parcial da área de exibição dos posters do $4^{\circ}$ Encontro Nacional de Espectrometria de Massa na Faculdade de Ciências da Universidade de Lisboa. Este encontro contou com 88 inscritos, 6 palestras convidadas, 18 comunicações orais e 62 posters. As apresentações em poster constituíram uma excelente oportunidade para o estabelecimento de contactos científicos, discussão de novas ideias e o forjar de novas colaborações

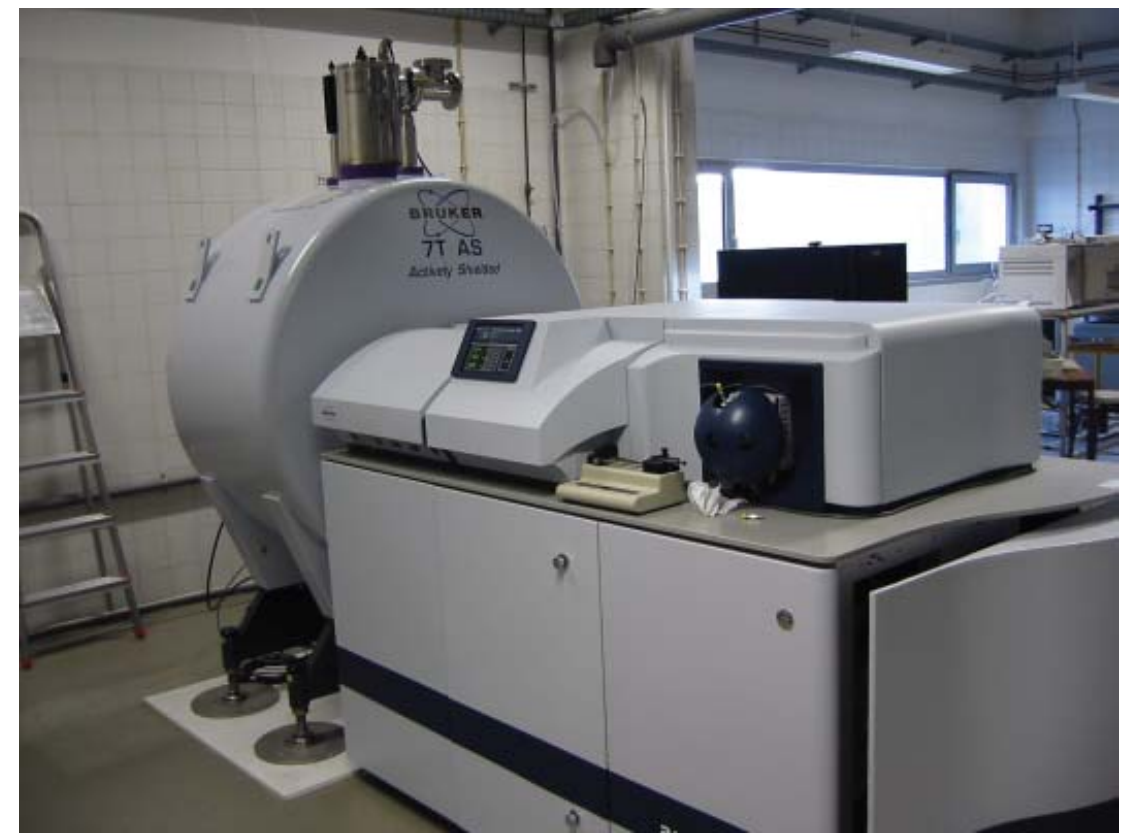

Figura 3 - Espectrómetro de massa de ressonância ciclotrónica de ião com transformada de Fourier (FTICR-MS) no Laboratório de FTICR e Proteómica da FCUL. Este equipamento permite determinar massas exactas com elevada resolução. Um exemplo das suas aplicações é a caracterização de proteínas intactas e suas modificações pós-traducionais. Permite ainda estabelecer a composição elementar de moléculas

participar, com vista a analisar o estado da arte da espectrometria de massa em Portugal e a sua evolução e afirmação como área estratégica de primeira linha e sua contribuição para a competitividade internacional de Portugal. A Rede Nacional de Espectrometria de Massa (rnem.fc.ul.pt) constitui a matriz organizadora da espectrometria de massa em Portugal, tendo actualmente nove NÓs que possuem diversos tipos de espectrómetros de massa modernos, incluindo um FTICR (Figura 3).

O encontro terminou com uma cerimónia de atribuição de prémios pelo representante da Fundação Jacqueline Dias de Sousa, Engenheiro Dias de Sousa, tendo o Dr. Bruno Manadas do Centro de Neurociências da Universidade de Coimbra recebido o prémio pela melhor comunicação oral, intitulada 
Proteomic analysis of an interactome for ion-form AMPA receptor subunits.

O licenciado em bioquímica Samuel Gilberto, do Centro de Quimica e Bioquímica da Faculdade de Ciências da Universidade de Lisboa, recebeu o prémio pela melhor apresentação em poster com o título Enhanced MALDIFTICR MS analysis of glycated fibrinogen peptides by methylglyoxal. A Professora Helena Florêncio encerrou o encontro, anunciando a realização do próximo em 2012.
$\mathrm{O} 4^{\circ}$ Encontro Nacional de Espectrometria de massa é dedicado à memória de John Fenn, falecido a 10 de Dezembro de 2010, tendo sido homenageado pelo Professor Albert Heck na sua palestra.

Carlos Cordeiro (cacordeiro@fc.ul.pt) Comissão Organizadora

\section{Modern Methods of Structure Elucidation - 2010}

O curso avançado Modern Methods of Structure Elucidation - 2010 (http://cqe.ist.utl.pt/events/mmse2010), organizado pelo Centro de Química Estrutural - Instituto Superior Técnico (CQE-IST), IST-UTL NMR Center of the Portuguese NMR Network, IST Node of the National MS Network - em colaboração com o Instituto Tecnológico e Nuclear (ITN), e apoiado pela Sociedade Portuguesa de Química, decorreu no passado mês de Dezembro entre os dias 13 e 17, no Instituto Superior Técnico (IST). O principal objectivo deste curso foi a transmissão de conhecimentos teóricos e teóricopráticos (aplicações, case-studies, demonstrações de equipamentos e hands-on training) dos métodos espectroscópicos, tais como Ressonância Magnética Nuclear em solução e de estado sólido, Ressonância Paramagnética Electrónica, Espectrometria de Massa e Difracção de Raios X. A escola MMSE-2010, evento único a nível nacional, juntou durante uma semana cerca de 60 participantes, entre os quais se encontraram os cientistas nacionais mais conceituados nas áreas de elucidação estrutural e jovens investigadores (bolseiros de investigação, estudantes de licenciatura, mestrado e doutoramento, investigadores pós-doutorados de várias universidades e institutos de investigação do país), num treino intensivo e eficiente (Figura 1).

O módulo introdutório da escola MMSE-2010, tutorado por especialistas vindos de diferentes centros de investigação de reconhecido mérito do país, tais como IST, Universidade Nova de Lisboa (UNL), Faculdade de Ciências da Universidade de Lisboa (FCUL), ITN e Instituto de Tecnologia Química e Biológica (ITQB-UNL), abordou as bases teóricas de cada técnica e as suas aplicações gerais.
O módulo dedicado a case-studies teve como foco a utilização das técnicas espectroscópicas mencionadas nas áreas de química, bioquímica, farmacologia e biologia estrutural. Nos seminários, os participantes tiveram a oportunidade de aplicar os conhecimentos teóricos adquiridos, estabelecendo a estrutura de um composto desconhecido a partir de dados espectroscópicos fornecidos (Figura 2). Por fim, as sessões práticas e as demonstrações dos equipamentos permitiram aos participantes um contacto muito próximo com cada técnica e o aprofundamento dos conhecimentos fornecidos nas aulas teóricas e nos seminários (Figura 3).

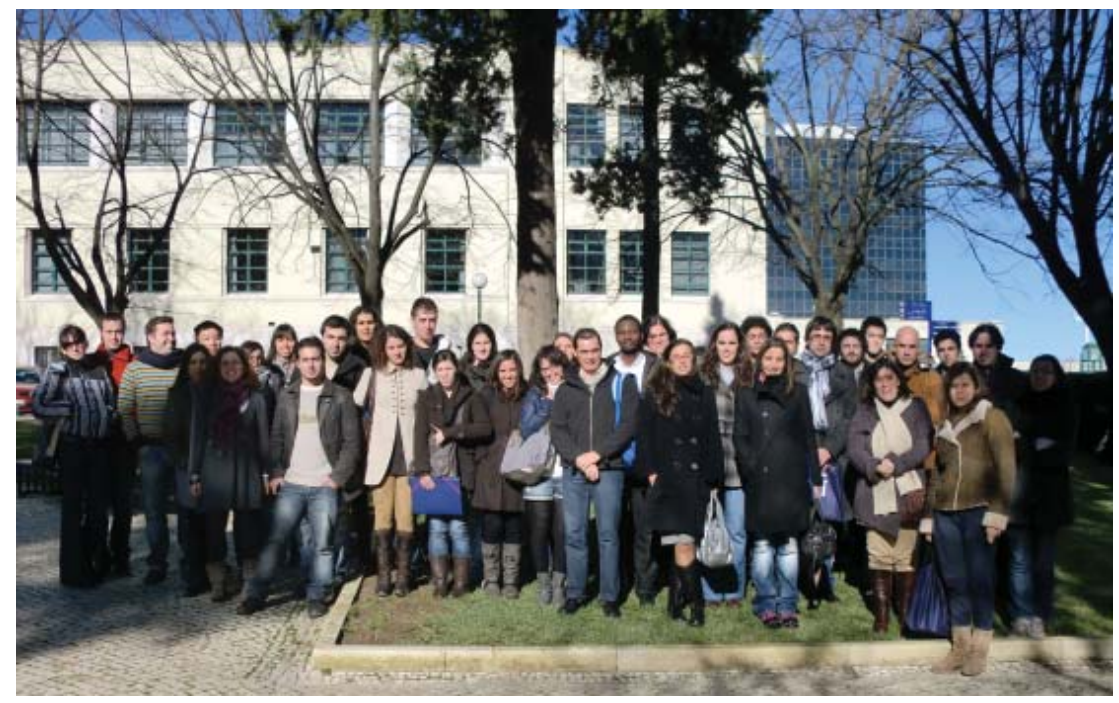

Figura 1 - Participantes da escola nacional dos métodos espectroscópicos MMSE-2010

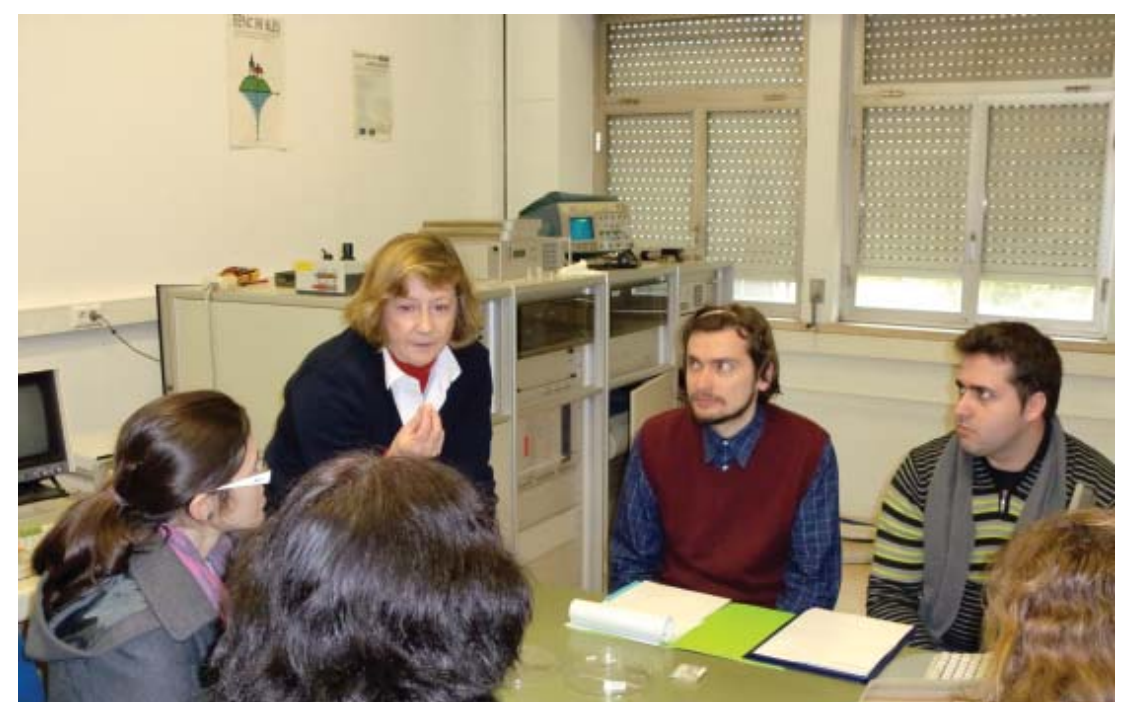

Figura 2 - Aplicação dos conhecimentos teóricos adquiridos pelos participantes 